\title{
Article \\ Will E-Cigarette Modified Risk Messages with a Nicotine Warning Polarize Smokers' Beliefs about the Efficacy of Switching Completely to E-Cigarettes in Reducing Smoking-Related Risks?
}

\author{
Bo Yang *, Juliana L. Barbati $\mathbb{1}$ and Yunjin Choi
}

check for updates

Citation: Yang, B.; Barbati, J.L.; Choi, Y. Will E-Cigarette Modified Risk Messages with a Nicotine Warning Polarize Smokers' Beliefs about the Efficacy of Switching Completely to E-Cigarettes in Reducing Smoking-Related Risks? Int. J. Environ. Res. Public Health 2021, 18, 6094. https://doi.org/10.3390/ ijerph18116094

Academic Editors: Olivia

A. Wackowski, Jennifer Pearson and Michelle Jeong

Received: 31 March 2021

Accepted: 2 June 2021

Published: 5 June 2021

Publisher's Note: MDPI stays neutral with regard to jurisdictional claims in published maps and institutional affiliations.

Copyright: (c) 2021 by the authors. Licensee MDPI, Basel, Switzerland. This article is an open access article distributed under the terms and conditions of the Creative Commons Attribution (CC BY) license (https:// creativecommons.org/licenses/by/ $4.0 /)$.
Department of Communication, University of Arizona, Tucson, AZ 85721, USA; jbarbati@email.arizona.edu (J.L.B.); ychoi@email.arizona.edu (Y.C.)

* Correspondence: byang1@arizona.edu; Tel.: +1-520-626-0231
Abstract: In the U.S., e-cigarette companies can apply for permission to use reduced or modified risk messages (MRMs) in their marketing materials. Because e-cigarette marketing materials should have a nicotine addictiveness warning, MRMs and a nicotine warning could appear together-resulting in a conflicting message. When reading a conflicting message, individuals assimilate evidence supporting their pre-existing beliefs and eventually develop stronger beliefs, diverging more from those with different pre-existing beliefs (i.e., polarization). This study examined if exposure to e-cigarette MRMs with a nicotine warning polarizes smokers' initially opposing beliefs about the efficacy of switching completely to e-cigarettes in reducing smoking-related risks, and if this polarization depends on individuals' need for closure. An online experiment randomized 761 U.S. adult smokers to either three MRMs with a nicotine warning or three control messages. People reported their perceived efficacy of switching completely to e-cigarettes at pre- and posttest and need for closure at pretest. Linear regression showed no polarization effects. Nonetheless, need for closure and pretest efficacy beliefs influenced message response: MRMs with a nicotine warning only enhanced efficacy beliefs of smokers with low pretest efficacy beliefs and low need for closure. Evaluation of e-cigarette mixed communication should consider individuals' motivational and cognitive differences.

Keywords: modified risk claims; e-cigarettes; nicotine addictiveness warning; opinion polarization; need for closure

\section{Introduction \\ 1.1. Background}

After being introduced to the U.S. market in 2007, e-cigarettes quickly gained popularity. While the long-term health effects of e-cigarettes await more research, existing evidence suggests that e-cigarettes may exude fewer toxins compared to combustible cigarettes [1-5]. As a result, there has been more discussion in recent years about encouraging a complete switch to e-cigarettes among smokers who otherwise are unable or unwilling to quit smoking [6-9]. Supposedly, this could reduce smokers' smoking-related health risks.

In the U.S., tobacco companies can submit applications (i.e., Modified Risk Tobacco Product Applications or MRTPAs) to the U.S. Food and Drug Administration (FDA) for using reduced or modified risk claims in their marketing materials [10]. The FDA thus far has received MRTPAs for several smokeless tobacco products (General Snus, Copenhagen, and Camel Snus), an electronic heated tobacco product (IQOS), and a reduced nicotine cigarette brand (VLN ${ }^{\mathrm{TM}}$ King) [11]. By March 2021, the FDA has permitted General Snus to use modified risk claims stating that their products pose lower levels of smoking-related risks than cigarettes and IQOS to claim that switching to their products reduces smokers' exposure to harmful substances [12]. E-cigarettes have been a central subject of the tobacco harm reduction discussion [6]. Following other tobacco products, e-cigarette MRTPAs may 
happen in the future. Thus, it is important to understand how consumers react to modified risk messages (MRMs) about e-cigarettes.

In the current study, we focus on the effects of e-cigarette MRMs combined with a nicotine addictiveness warning label. In August 2018 [13], the FDA required that e-cigarette promotion materials include a warning label indicating that e-cigarettes contain nicotine, an addictive chemical. Thus, an MRM might appear in tandem with a nicotine warning. However, a combination of an MRM with a nicotine warning could result in a conflicting message (i.e., a message that both supports and opposes the same subject) and could be perceived as ambiguous [14]. Both qualitative [15-17] and quantitative studies [18] have documented such a possibility.

Conflicting health messages may adversely influence people's knowledge and beliefs [14,19-22] about a health issue. For instance, Nagler and colleagues [20] found that exposure to conflicting recommendations about mammography increased people's confusion, negative affective responses, and negative reactions towards research and recommendations about cancer prevention. Similarly, Chang [22] found that news presenting conflicting evidence about health effects of drinking milk and jogging produced decreased message credibility, less positive attitudes towards health research, greater uncertainty, and weaker message compliance intentions.

A few studies have also examined e-cigarette conflicting communication. A national survey [23] in 2014 found that U.S. adults' exposure to conflicting information about ecigarettes was associated with weaker support for several e-cigarette regulation policies, including a policy about enforcing an addiction warning label. An experimental study [18] among U.S. nonsmokers found that the addition of MRMs to an e-cigarette warning on ecigarette packaging increased perceived message ambiguity, and in turn reduced perceived warning effectiveness, as well as intentions to stay away from e-cigarettes. In another experiment [24], 2056 U.S. adults reported no differences between conflicting e-cigarette messages and control messages whereas positive and negative e-cigarette messages produced responses consistent with the messages. Very recently, scholars [25] found that personal characteristics impacted people's responses to e-cigarette messages mentioning both positive and negative product effects. Specifically, among those with a low information avoidance tendency, exposure to conflicting e-cigarette information produced more confusion than one-sided anti-e-cigarette messages or control messages. Among those with a high information avoidance tendency, however, message effects did not differ.

Overall, past studies have delivered some useful insights into how people respond to ecigarette messages when they include both supportive and opposing information. However, no studies have considered the role of individuals' initial beliefs about a message topic (i.e., e-cigarettes in the present context)—a very important factor shaping mixed or conflicting message responses according to the communication and psychology literature [26,27]. Our study aims to perform a preliminary examination of this issue. Specifically, based on the biased assimilation and opinion polarization literature, we examined if smokers who initially differed in their perceived efficacy of switching completely to e-cigarettes in reducing smoking-related risks would become stronger in their beliefs after exposure to MRMs with a nicotine warning. Additionally, following Yang and colleagues [25] and prior studies on biased assimilation of mixed health communication $[28,29]$, we examined another personality variable, need for closure, in the interplay of initial e-cigarette efficacy beliefs and MRMs with a nicotine warning on smokers' posttest perceived e-cigarette efficacy in reducing smoking-related health risks.

\subsection{Biased Assimilation and Opinion Polarization}

When people are exposed to mixed or conflicting information, they tend to selectively attend to information that confirms their pre-existing beliefs, while ignoring or discounting information that challenges them [30,31]. For instance, upon exposure to messages including evidence that both supports and refutes the death penalty, supporters of the death penalty only attend to evidence in support of the death penalty while opponents 
only focus on the opposing evidence [30]. This phenomenon is termed biased assimilation. Biased assimilation posits that people's initial stance on an issue will become stronger after being exposed to a conflicting message. This attitude strengthening leads to the gap between those initially disagreeing with each other to become wider-referred to as opinion polarization [30]. In other words, exposure to conflicting information will lead people to disregard the information that does not coincide with their pre-existing attitudes. Simultaneously, they will attend to the information that they already agree with, leading them to feel even stronger in their opinion. Eventually, people's original opposing opinions diverge into two opposite extremes.

Biased assimilation and attitude polarization have been documented in various domains [30,32-35], including the health domain [28,29,36,37]. For instance, Kahan and colleagues [28] found that individuals who initially held opposing views towards the HPV vaccination mandate disagreed more with each other following exposure to messages including both pro- and counter-vaccine arguments (vs. a control message). Similar to Kahan and colleagues and more relevant to the present study, Ofori-Parku [36] presented a message mentioning both risks and benefits of smoking to college students who held cultural worldviews that either supported or opposed smoking. Following message exposure, researchers asked students to report perceived smoking risks. Results revealed that those who saw the mixed message (vs. those who did not) were more convinced of their original position after message exposure.

To the best of our knowledge, no study has tested biased assimilation and attitude polarization in the context of e-cigarettes. However, similar to previously examined issues (e.g., HPV vaccine) in the polarization literature, there are different beliefs and attitudes regarding e-cigarettes [38], particularly regarding their potential as a less harmful smoking alternative. As such, exposure to mixed e-cigarette messages may produce biased assimilation and divergent opinions. Specifically, according to prior empirical findings about biased assimilation and opinion polarization $[28,29,36,39]$, smokers exposed to MRMs with a nicotine warning might choose to focus on different information depending on their initial efficacy beliefs about switching completely to e-cigarettes in reducing smoking-related risks. As a result, they may report polarized efficacy beliefs after message exposure. We make the following prediction:

Hypothesis 1 (H1). Exposure to MRMs with a nicotine warning polarizes smokers who initially hold different beliefs about the efficacy of switching completely to e-cigarettes in reducing smokingrelated risks such that: (a) exposure to MRMs with a nicotine warning (vs. control messages) increases efficacy beliefs among smokers with high efficacy beliefs at pretest; $(b)$ exposure to MRMs with a nicotine warning (vs. control messages) decreases efficacy beliefs among smokers with low efficacy beliefs at pretest.

We focused on people's beliefs about the efficacy of switching to e-cigarettes in reducing smoking-related risks because tobacco companies' modified risk marketing is very likely to focus on changing such a belief. For example, the MRM from IQOS says: "Switching completely from conventional cigarettes to the IQOS system significantly reduces your body's exposure to harmful or potentially harmful chemicals" [40]. Additionally, beliefs about the efficacy of an issue in addressing a problem have been an important outcome in prior attitude polarization literature, such as the original study on this concept (i.e., the perceived deterrent efficacy of the death penalty) [30].

\subsection{Need for Closure}

One important goal of modified risk communication is to convey knowledge about a modified risk tobacco product so that consumers can make more informed decisions [10]. However, individuals differ from each other in their knowledge acquisition motives [41]. Such differences may influence the processing of modified risk information. As a result, evaluation of modified risk communication should consider individuals' differences in their knowledge acquisition motives. In this study, we examined need for closure-a 
major motivational factor governing knowledge acquisition and an important individual difference variable that impacts attitudes and attitude change [42].

Need for closure describes "individuals' desire for a firm answer to a question and an aversion toward ambiguity" [43] (p. 264). The construct comes from Kruglanski's lay epistemic theory [41]. Lay epistemic theory examines the process through which people acquire and modify their knowledge; this theory has received much discussion in the persuasion and attitude change literature [44].

Individuals' need for closure can be influenced by situational factors, such as time constraints, rewards for being closed-minded, environmental noise, and mental fatigue (i.e., fatigue after prolonged cognitive activity). Additionally, the construct is known to vary as an individual difference variable [45]. Individuals high on need for closure prefer order, predictability, and decisiveness, but dislike ambiguity and inconsistent information. As a result, high need-for-closure people usually seek prompt and permanent cognitive closure. While processing information and making decisions, those high on need for closure "seize" quickly on accessible cues and then "freeze" existing beliefs and resist new information [43]. Compared with those high on need for closure, individuals low on need for closure have increased open-mindedness. They consider various perspectives before making a judgment [43]. These differing tendencies among high and low need-forclosure people result in a wide range of social-cognitive phenomena [46]. For instance, high need-for-closure people report greater use of readily accessible information, preference for prototypic (vs. diagnostic) information, and greater confidence in subjective judgments.

The differences between people with low and high need for closure in information processing and tolerance of ambiguity suggest that need for closure could influence how individuals respond to conflicting messages. Indeed, Nan and her colleague [29] asked college students to view blogs containing positive and negative opinions about the HPV vaccine and assessed students' chronic need for closure. They found that need for closure worked in tandem with students' beliefs about the effectiveness of vaccinations in general to influence students' responses to the conflicting blogs. Specifically, among only individuals with high need for closure, opinion polarization occurred: those with high initial vaccination effectiveness perceptions reported higher HPV vaccine effectiveness, while those with low initial perceptions reported lower HPV vaccine effectiveness after being exposed to the conflicting blogs. Nan and her colleague's study revealed that the addition of need for closure can lead to a better understanding of belief polarization.

Extending upon Nan and her colleague's study, we chose to explore whether need for closure moderates the polarization effects predicted in H1. Additionally, need for closure is an important epistemic motivational variable [42] and may play an important role in the perceptions of modified risk communication and advertisements. Recently, scholars [25] found that smokers' information avoidance tendency was closely related to their responses to e-cigarette mixed messages. Need for closure has long been discussed as an important variable related to individuals' information acquisition tendencies and behaviors [45,47-49]. By examining need for closure, we logically extended previous findings regarding the role of individual difference variables in shaping responses to mixed e-cigarette messages. Informed by Nan and her colleague's study [29], we predict:

Hypothesis 2 (H2). The effects described in H1 will be more pronounced among smokers with high (vs. low) need for closure.

\section{Materials and Methods}

\subsection{Design, Participants, and Procedure}

This study is part of a larger experiment on e-cigarette and nicotine risk communication. Specifically, the whole experiment included five message conditions ( $n=1906$; for a detailed description of the five conditions, see our earlier publications $[50,51])$. In the current study, we analyzed data from only two of the five message conditions relevant 
to our hypotheses ( $n=761$; discussed below). The other three conditions in the larger experiment were excluded.

The sample ( $n=761 ; \geq 18$ years old) consisted of primarily current smokers who reported having consumed at least 100 cigarettes in their life, and currently used cigarettes "every day" or "some days". The sample also had a small number of former smokers who had consumed at least 100 cigarettes in their life and had quit smoking in the past two years. Similar to previous tobacco communication and behavior research [52-55], we recruited participants from Toluna, a commercial research company. Toluna has "the worlds' largest online social voting community" (p. 1) [56], with more than 36 million registered participants available for various types of online surveys around the world. In the U.S., Toluna reserves nearly 7 million people who are recruited through various strategies (e.g., web banners, website referrals, pay-per-click, affiliate marketing, and email). Toluna aims to create a diverse participant community similar to the general population distribution (for more data quality information, see https://tolunacorporate.com/wpcontent/uploads/2020/07/ID_080-Quality-eBook_v02-1.pdf) (accessed on 3 June 2021). Upon panel registration, Toluna collects participants' personal information, including tobacco use history. Once a study becomes available, Toluna randomly selects eligible participants to contact about the study. For our study, participants needed to meet the age and smoking behavior requirements specified above. Participants who completed our study received points that could be redeemed for cash or vouchers for store credit.

The study was implemented on Toluna's web portal. Participants first completed an electronic consent form. In the experiment, participants answered questions about their demographics, their tobacco use, and beliefs about e-cigarettes, including their pre-existing perceived efficacy of switching completely to e-cigarettes in reducing smoking-related health risks. Then, they were randomly assigned to a message condition. To reiterate, the purpose of the present study is to explore whether MRMs with a nicotine warning have polarization effects. In addressing similar questions, previous biased assimilation and polarization research has compared a mixed message condition with a control condition (e.g., no message or a brief message without arguments for each side) [28,29,36,39]. Additionally, the FDA requires e-cigarette marketing materials to include a nicotine warning label. As such, when smokers see MRMs in e-cigarette modified risk marketing or advertising, most likely they will see the messages in tandem with a nicotine warning label instead of MRMs alone. Based on this logic and previous research, we selected only two conditions from the larger experiment: (1) MRMs with a nicotine warning condition and (2) a control condition. In each condition, participants read three messages one after another in a random order. After all messages were shown, participants reported outcome measures, including their perceived efficacy of switching completely to e-cigarettes in reducing smoking-related risks.

The study was conducted in accordance with the Declaration of Helsinki, and its protocol was approved by Georgia State University's Institutional Review Board (IRB number: H18570). All participants received a debriefing message and were directed to smoking cessation resources at the end of the study.

\subsection{Message Stimuli}

The MRMs with a warning condition included three MRMs plus the same FDA requested nicotine warning label. The MRMs across three messages aimed to communicate that switching completely to e-cigarettes could reduce smokers' risks for smoking-related diseases, and if smokers cannot quit smoking, they can instead switch completely to ecigarettes. We developed the message content through a review of existing e-cigarette messages and e-cigarette health risk literature as well as focus group discussions (for detailed message development, please see our other publications [16,57]). The MRMs were delivered in a format informed by existing MRMs submitted by tobacco companies, as well as our own knowledge about e-cigarette advertisements. The nicotine warning label was designed and formatted according to the FDA's standards. It reads: "This product contains nicotine. Nicotine is an addictive chemical." The control condition included 
three bottled water ads. Similar to the modified risk stimuli, bottled water ads each had textual information placed against a large visual background (for detailed stimuli, see the Supplementary Material Figure S1). The amount of time spent viewing the message stimuli did not differ based on condition, $F(1,759)=0.65, p=0.42, \eta^{2}=0.001$.

\subsection{Key Measures}

Pretest and posttest perceived efficacy of switching completely to e-cigarettes were assessed with the same scale [58]. Before and after message exposure, participants reported their level of agreement with three items on a 1 to 9 scale: "Switching completely to ecigarettes is effective at reducing my chances of getting cancer", "If I switch completely to e-cigarettes, I am less likely to get a serious disease", and "If I switch completely to e-cigarettes, I will have fewer health risks". We averaged ratings across these three items to create a composite score for pretest (perfect model fit due to a saturated model; $\mathrm{M}=4.73$, $\mathrm{SD}=0.95, \alpha=0.94$ ) and posttest perceived efficacy (saturated model; $\mathrm{M}=5.19, \mathrm{SD}=2.44$, $\alpha=0.96)$.

Need for closure was assessed with a pre-established scale [59]. Participants indicated their level of agreement across 15 items on a 1 to 10 scale. Example items included "I don't like situations that are uncertain", "I dislike questions which could be answered in many different ways", and "I dislike unpredictable situations". Ratings of the 15 items were averaged to create a composite score (one-factor model: $\chi^{2}(75)=413.99, p<0.001$, $\mathrm{RMSEA}=0.077,90 \% \mathrm{CI}[0.070,0.084], \mathrm{SRMR}=0.056, \mathrm{CFI}=0.903 ; \mathrm{M}=5.03, \mathrm{SD}=2.48$, $\alpha=0.87)$.

Control variables assessed and controlled for included gender, race/ethnicity, age, education, nicotine dependence $[60,61]$, past quitting attempt, current and ever e-cigarette use, and ever switch to a lower tar or nicotine cigarette.

\subsection{Analysis Plan}

To test our hypotheses, we performed one ordinary least square regression analysis. The regression model had posttest perceived efficacy of switching completely to e-cigarettes as the dependent variable and controlled for the covariates listed above. Key independent variables included message condition (MRMs vs. control), pretest perceived efficacy of switching completely to e-cigarettes, and need for closure, as well as their two- and threeway interactions. To avoid multicollinearity, composite scales in the interaction terms were mean-centered before forming products.

Our H1 predicted that (a) exposure to MRMs with a nicotine warning increases efficacy beliefs among smokers with high pretest efficacy beliefs and (b) exposure to MRMs with a nicotine warning decreases efficacy beliefs among smokers with low pretest efficacy beliefs. This implies a significant two-way interaction between pretest perceived efficacy of switching completely to e-cigarettes and message condition. $\mathrm{H} 2$ predicted that the prediction posed in $\mathrm{H} 1$ should be more pronounced amongst smokers with high (vs. low) need for closure, implying a three-way interaction among pretest perceived efficacy, message condition, and need for closure. Significant interaction terms were probed with Hayes' PROCESS macro [62] to identify whether the patterns were consistent with H1 and H2. Following Hayes' suggestions, to test H1, we explored the relationship between message condition and posttest perceived efficacy at two values (high: $\mathrm{M}+1 \mathrm{SD}$; low: $M-1 S D)$ of pretest perceived efficacy. To test H2, we explored the two-way interaction between message condition and pretest perceived efficacy at high (M + 1SD) and low levels $(\mathrm{M}-1 \mathrm{SD})$ of need for closure. Data analyses were conducted in Stata v14.1 and SPSS v24.

\section{Results}

\subsection{Sample Characteristics}

Table 1 lists the sample characteristics. According to Table 1, amongst all participants, $51.5 \%$ identified as female, $73.9 \%$ identified as White, and 50.3\% had at least some college education. The majority of participants smoked daily $(63.3 \%)$, and more than half had 
attempted to quit smoking in the past year (52.6\%). Nearly 50\% were currently using e-cigarettes. The sample included similar numbers of people from different age groups $(\mathrm{M}=43.77, \mathrm{SD}=15.51)$.

Table 1. Characteristics of study participants.

\begin{tabular}{|c|c|}
\hline & $\begin{array}{r}\text { Overall } \\
(n=761)\end{array}$ \\
\hline \multicolumn{2}{|l|}{ Gender } \\
\hline Male & 48.0 \\
\hline Female & 51.5 \\
\hline Transgender & 0.5 \\
\hline \multicolumn{2}{|l|}{ Age } \\
\hline $18-29$ & 22.5 \\
\hline $30-44$ & 33.0 \\
\hline $45-59$ & 25.1 \\
\hline $60+$ & 19.4 \\
\hline \multicolumn{2}{|l|}{ Race } \\
\hline White & 73.9 \\
\hline Black or African American & 15.2 \\
\hline American Indian or Alaska Native & 1.4 \\
\hline Asian & 3.8 \\
\hline Other & 5.7 \\
\hline \multicolumn{2}{|l|}{ Ethnicity } \\
\hline Hispanic & 12.4 \\
\hline Non-Hispanic & 87.6 \\
\hline \multicolumn{2}{|l|}{ Education } \\
\hline Less than high school & 8.1 \\
\hline High school & 31.5 \\
\hline Some college & 33.0 \\
\hline Bachelor or higher degree & 27.3 \\
\hline \multicolumn{2}{|l|}{ Daily Smoker } \\
\hline Yes & 63.3 \\
\hline No & 36.7 \\
\hline \multicolumn{2}{|l|}{ E-Cigarette Use } \\
\hline Current & 46.4 \\
\hline Former & 24.4 \\
\hline Never & 29.2 \\
\hline \multicolumn{2}{|l|}{ Current Cigarette Smoking } \\
\hline Yes & 95.9 \\
\hline No, former smoker & 4.1 \\
\hline \multicolumn{2}{|l|}{ Tried to Quit in the Past 12 Months } \\
\hline Yes & 52.6 \\
\hline No & 47.4 \\
\hline
\end{tabular}

\subsection{Hypothesis Testing}

Results are shown in Table 2 and Figure 1. MRMs produced higher perceived efficacy of switching completely to e-cigarettes than the control messages $(b=0.12, p=0.002$, $\left.\eta^{2}=0.005, r=0.07\right)$. However, this main effect was further qualified by a two-way interaction $\left(\mathrm{b}=-0.04, p=0.007, \eta^{2}=0.004, r=0.06\right)$. Specifically, as shown in Figure 1, amongst individuals who held high levels of efficacy beliefs at pretest, peoples' posttest perceived efficacy did not differ based on message condition $(b=0.01, p=0.91)$; amongst individuals who held low levels of efficacy beliefs at pretest, MRMs produced higher posttest perceived efficacy than the control messages $(b=0.25, p<0.001)$. Because this pattern was inconsistent with H1, H1 was rejected. 
Table 2. Regression analyses predicting posttest perceived efficacy of switching completely to e-cigarettes.

\begin{tabular}{|c|c|c|c|c|}
\hline Predictors & $\begin{array}{l}\text { Unstandardized } \\
\text { Coefficient }\end{array}$ & Standard Error & $\begin{array}{c}\text { Part } \\
\text { Correlation }\end{array}$ & $p$ Value \\
\hline Male (vs. other) & -0.07 & 0.12 & -0.01 & 0.56 \\
\hline Age & -0.01 & 0.00 & -0.06 & 0.01 \\
\hline Non-Hispanic White (vs. Non-Hispanic other) & -0.25 & 0.23 & -0.03 & 0.28 \\
\hline Non-Hispanic Black (vs. Non-Hispanic other) & -0.10 & 0.27 & -0.01 & 0.70 \\
\hline Hispanic (vs. Non-Hispanic other) & -0.29 & 0.27 & -0.03 & 0.29 \\
\hline Below college education (vs. other) & -0.05 & 0.12 & -0.01 & 0.68 \\
\hline Current e-cigarette users (vs. never) & 0.15 & 0.16 & 0.02 & 0.35 \\
\hline Ever but not current e-cigarette users (vs. never) & 0.09 & 0.16 & 0.01 & 0.57 \\
\hline Nicotine dependence & 0.10 & 0.04 & 0.05 & 0.02 \\
\hline Past quit attempt (vs. no) & 0.19 & 0.13 & 0.03 & 0.14 \\
\hline Ever switch to a lower tar or nicotine cigarette (vs. no) & 0.34 & 0.13 & 0.06 & 0.01 \\
\hline $\begin{array}{l}\text { Modified risk messages with a nicotine warning (MRMs } \\
\text { vs. control) }\end{array}$ & 0.12 & 0.04 & 0.07 & 0.00 \\
\hline Pretest perceived efficacy (Efficacy) & 0.78 & 0.05 & 0.38 & 0.00 \\
\hline Need for closure (NC) & 0.07 & 0.12 & 0.01 & 0.57 \\
\hline Efficacy $\times$ MRMs & -0.04 & 0.02 & -0.06 & 0.01 \\
\hline Efficacy $\times$ NC & -0.06 & 0.05 & -0.03 & 0.19 \\
\hline $\mathrm{MRMs} \times \mathrm{NC}$ & -0.01 & 0.04 & -0.00 & 0.86 \\
\hline Efficacy $\times$ MRMs $\times \mathrm{NC}$ & 0.04 & 0.02 & 0.06 & 0.01 \\
\hline Total $R^{2}$ & 0.60 & & & \\
\hline Adjusted $R^{2}$ & 0.59 & & & \\
\hline
\end{tabular}

Note. Bold numbers represent significance at $p<0.05$.

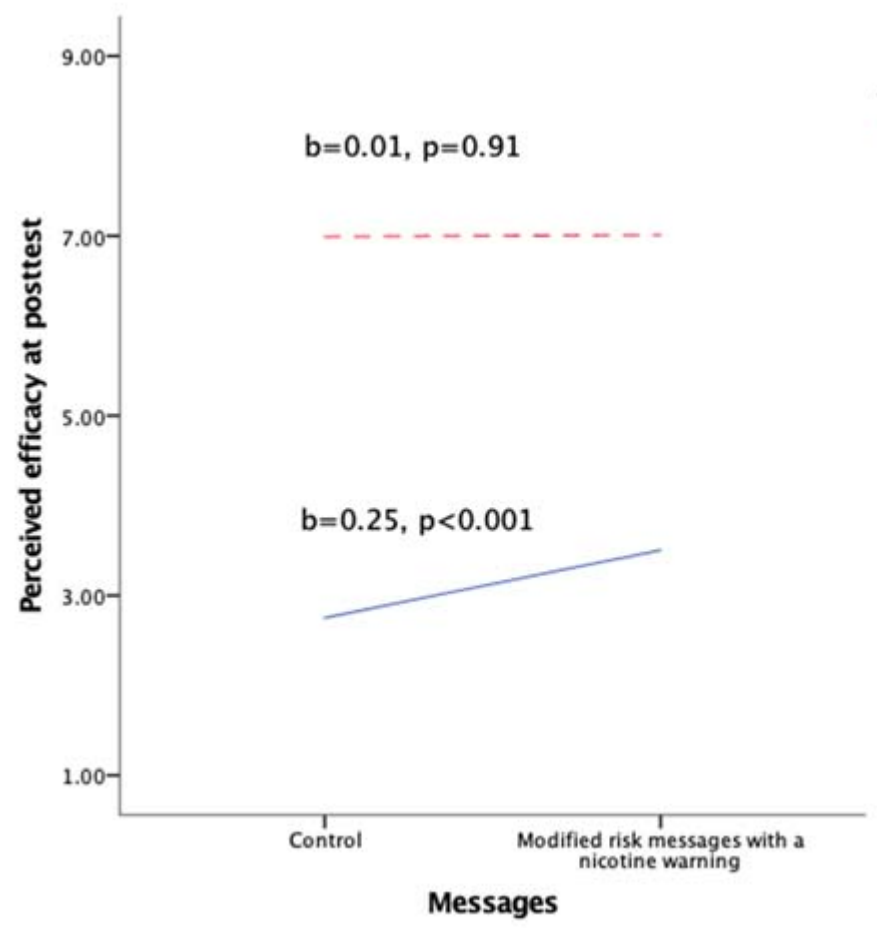

Figure 1. Two-way interaction between message condition and pretest perceived efficacy of switching completely to e-cigarettes in reducing smoking-related risks.

In testing $\mathrm{H} 2$, we found a significant three-way interaction $\left(b=0.04, p=0.01, \eta^{2}=0.003\right.$, $r=0.06$; Table 2). Further exploration (see Figure 2) revealed that amongst individuals with high levels of need for closure, regardless of their levels of efficacy beliefs at pretest, MRMs did not yield different efficacy beliefs compared to the control messages (high: $\mathrm{b}=0.09, p=0.15$; low: $\mathrm{b}=0.14, p=0.16$ ). Amongst individuals with low levels of need 
for closure, when they held high levels of pretest efficacy beliefs, exposure to MRMs did not influence their efficacy beliefs $(b=-0.07, p=0.38)$; when individuals held low levels of pretest efficacy beliefs, exposure to MRMs increased their perceived efficacy of switching completely to e-cigarettes in reducing smoking-related risks compared to the control messages $(b=0.36, p<0.001)$. This interaction suggests that message condition interacted with pretest efficacy beliefs only amongst those with low need for closure, and the interaction did not show belief polarization. $\mathrm{H} 2$ was rejected.

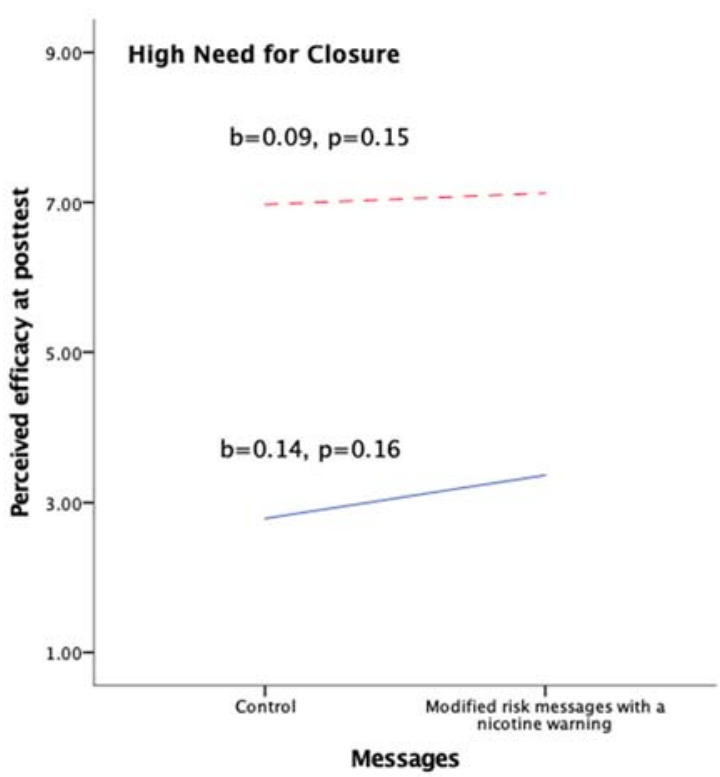

(a)

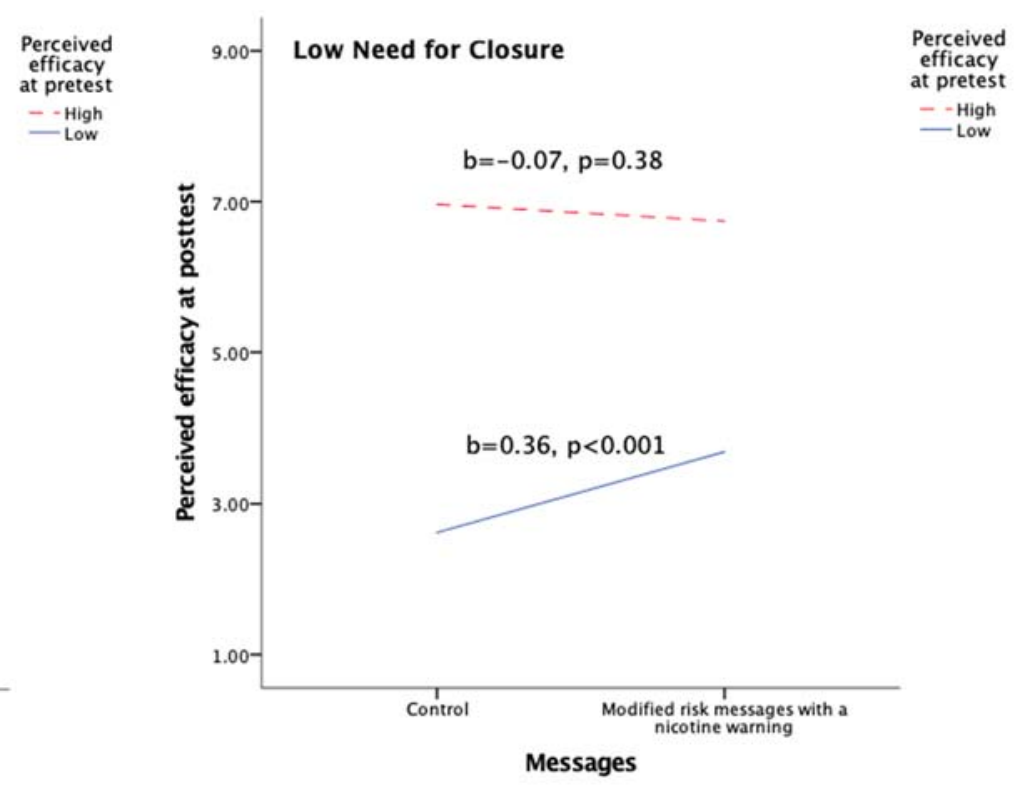

(b)

Figure 2. Three-way interaction between message condition, need for closure, and pretest perceived efficacy of switching completely to e-cigarettes in reducing smoking-related risks: (a) high need for closure; (b) low need for closure.

\section{Discussion}

We posed two hypotheses to test whether e-cigarette MRMs with a nicotine addictiveness warning label would polarize smokers' beliefs about the harm reduction efficacy of switching completely to e-cigarettes (i.e., increase the divergence of pre-existing efficacy beliefs). We first predicted that after observing MRMs with a warning label (vs. control messages), smokers with differing pre-existing efficacy beliefs would increase in the strength of their pre-existing beliefs, resulting in a wider belief gap. Our findings did not support this prediction. Instead, we found that MRMs with a warning increased the efficacy beliefs of smokers with low pretest efficacy beliefs and had no effect on smokers with high pretest efficacy beliefs. Thus, MRMs with a warning actually narrowed the gap between smokers with different pre-existing efficacy beliefs.

Our second hypothesis introduced need for closure, an individual motivational variable that can influence the processing of conflicting information. We expected that smokers with high (vs. low) need for closure would be more likely to report belief polarization. We failed to support this hypothesis: amongst smokers with high need for closure, regardless of their pretest perceived efficacy about switching completely to e-cigarettes, MRMs with a warning did not influence their posttest efficacy beliefs. Amongst smokers with low need for closure, MRMs with a warning increased the efficacy beliefs of only those holding low pre-existing efficacy beliefs. This finding is similar to what we identified for $\mathrm{H} 1$, which suggests that it could be smokers with low need for closure and low pre-existing efficacy beliefs that drove our findings for $\mathrm{H} 1$.

Taking all the findings together, we are unable to conclude that exposure to MRMs with a nicotine warning polarizes smokers' beliefs about the efficacy of switching completely 
to e-cigarettes in reducing smoking-related risks even when considering need for closure. Our findings are inconsistent with previous biased assimilation and belief polarization literature $[28,29,37]$, which might be due to the following reasons.

First, smokers with high pretest efficacy beliefs might have experienced a ceiling effect. Thus, MRMs with a warning would not exert a significant effect on them. Second, people with high need for closure tend to have a greater risk aversion tendency [63]. Because e-cigarettes are widely known as a risky product [64], those high on need for closure were not influenced by the MRMs possibly due to a salient risk aversion tendency. Third, in past biased assimilation and polarization studies [28-30,34,35], the conflicting messages were usually more balanced in how they presented conflicting information. For example, in Nan and Daily's study [29], the supportive and oppositional HPV blogs were equal in length and design. In the current study, our MRMs were much longer, more colorful, and conveyed more health effect evidence than the nicotine warning label. Additionally, the background visuals tended to be more consistent with the overall tone of the MRMs. This might have reduced people's processing of the nicotine warning label and decreased the impact of the overall messages, affecting our capacity to produce findings consistent with former research. However, according to tobacco industry's common advertising strategies and existing MRMs, real-world modified risk ads might be similar to our stimuli that will use visuals appealing to people's positive emotions in support of MRMs. Future research may want to explore how message design factors influence the processing of MRMs and a health warning and the role of individuals' cognitive and motivational factors in this process. Finally, our results may be a product of our sample, which only included smokers. It is possible that smokers perceived MRMs with a warning differently than nonsmokers. Indeed, Katz and colleagues [18] found that perceptions of ambiguity differed based on smoking status. Nonsmokers perceived MRMs with a warning as ambiguous, while smokers did not. The same might have occurred in our smoker sample. Additionally, smokers might have been engaged in motivated reasoning [65] and thus were more likely to focus on the portion of the messages that suggested they could continue using nicotine products. Due to the potential lack of perceptions of ambiguity in our sample, and the potential for motivated reasoning, our expected polarization effects were limited. Given the novelty of our hypotheses, to better explain our findings, we encourage future research to further examine these relationships.

While our results did not support the notion of MRMs with a nicotine warning leading to attitude polarization, amongst smokers with low pretest efficacy beliefs and low need for closure, MRMs with a nicotine warning increased posttest efficacy beliefs; nonetheless, for smokers high in need for closure, MRMs with a nicotine warning did not have any effect. This indicates that smokers with high need for closure and low pretest efficacy beliefs might have more heavily considered the information against e-cigarettes and were less swayed in the direction of the MRMs compared to their low need-for-closure counterparts.

Our study provides important practical implications. When the FDA reviews Modified Risk Tobacco Product Applications (MRTPAs) from tobacco companies, it is important to consider whether consumers can correctly understand tobacco companies' promotional materials regarding modified risk [10]. In MRTPAs, modified risk claims usually appear with some warning. In this case, our study suggests that consumers' understanding of modified risk from MRMs can be influenced by people's cognitive and motivational attributes: specifically, their pre-existing beliefs about the modified risk statement and their need for closure. Our study found that MRMs with a warning had a main effect in enhancing beliefs consistent with the MRMs. However, when considering pretest efficacy beliefs and need for closure, we found that the main message effect was significant only amongst those with low pretest efficacy beliefs and low need for closure. The specific finding that MRMs with a warning had no influence amongst smokers with low pretest efficacy beliefs and high need for closure may indicate a missed harm reduction opportunity. Based on our findings, evaluation of MRMs with a warning should also consider consumers' motivational and cognitive traits that might influence their understanding of the modified 
risk statements. Notably, while need for closure can be considered a stable trait, it can be impacted by certain situational variables [46]. For instance, situations including less time for decision making, high mental fatigue (i.e., fatigue after prolonged cognitive activity), perceived low attractiveness of a task, increased difficulty of information processing and comprehension, as well as noisy environments can induce high need for closure [46]. This suggests that how and where people process MRMs may influence people's understanding of MRMs as it concerns need for closure. The FDA requires that tobacco companies provide sample marketing materials and describe their promotion strategies in their MRTPAs [10]. We suggest that such discussion may consider the specific marketing format and channel of MRMs that can influence consumers' level of need for closure. For instance, direct mail and brochures might be designed to present a lot of information. By contrast, product packaging might show less information. Hence, processing direct mail and brochures vs. product packaging might be more cognitively demanding and can easily lead to cognitive closure. As a result, interpretations of MRMs and warning messages on direct mail and brochures may be different from those of product packaging. Specifically, high levels of need for closure induced by cognitively demanding materials might interfere with people's understanding of modified risk information. As such, the FDA might also want to regulate the amount of information and design of modified risk marketing materials to make sure MRMs and warning information can be accurately understood.

Our study is limited in using a convenience sample. Although the sample is diverse in terms of demographics, it cannot accurately represent all U.S. smokers. Additionally, participants only viewed the stimuli for a short time in an artificial environment and reported their efficacy beliefs immediately following message exposure. Due to such a design, we cannot rule out any demand effects or assure that our findings remain in the long term. Future research can test messages using a longitudinal design that implements message exposure and measurement at different times [66]. Furthermore, due to the study design, we could not assess how our messages affect smokers' behavior. Given behavioral change is an important focus of tobacco control interventions, future research should also include behavior as an outcome and assess how polarized beliefs influence tobacco use behaviors. In this study, we presented a set of three MRMs with different designs to smokers. Although this reduced the threat of presenting only a single message and mimicked real-life situations where smokers may see multiple messages about e-cigarettes, the fixed message content and dosage might still affect the validity of our findings [67]. Particularly, our manipulation of the MRMs included many visuals in a positive tone. Though they were designed based on our knowledge of e-cigarette advertising, such a design might interfere with smokers' perceptions of the messages being mixed or conflicting. Future research should vary the content and number of messages to better understand the message effects. Notably, our findings about the interaction between pretest efficacy beliefs, message condition, and need for closure had a small effect size $(r=0.06)$. The effect size is comparable with other communication research. For example, about $25 \%$ of communication studies have effect sizes smaller than $r=0.10$ [68]. Media campaigns for smoking prevention and cessation have an average effect size of $r=0.03$ [69]. Given tobacco messages could be seen by a large number of people, small message effects still deserve merit [70]. However, the small effect size of our findings might also suggest the presence of some methodological limitations we identified above, which highlights the importance of conducting replication research beyond our initial study.

Besides encouraging future replication studies, our study points out several future research directions. First, given nonsmokers are also an important population in evaluating MRMs, future research should examine our research questions among nonsmokers. Additionally, future research may want to manipulate need for closure through situational cues (e.g., time for information processing or mental fatigue) to better explore the role of need for closure in response to MRMs with a warning or other conflicting e-cigarette messages. Additionally, future research should examine the impact of MRMs with negative health warnings in other formats (e.g., marketing brochure, package labeling, fact sheet), with 
other designs, and for other potentially less harmful tobacco products. In sum, studying the effects of communication about potentially less harmful tobacco products is important but challenging. Because the current communication environment about e-cigarettes contains mixed information $[9,69,71,72]$, it is critical to build upon the line of research on the effects of mixed e-cigarette messages using a motivational cognition framework.

\section{Conclusions}

This study tested how exposure to e-cigarette modified risk messages (MRMs) with a nicotine addictiveness warning would impact smokers' posttest efficacy regarding switching completely to e-cigarettes by applying a motivational cognition framework involving biased assimilation, attitude polarization, and need for closure. Our findings did not support the notion that MRMs with a nicotine warning would polarize smokers who initially held differing efficacy beliefs about the efficacy of switching completely to e-cigarettes in reducing smoking-related risks. Nonetheless, we found that need for closure and people's initial efficacy beliefs worked in tandem to influence message response: MRMs with a nicotine warning only enhanced efficacy beliefs of smokers with low initial efficacy beliefs and low need for closure. Consistent with a recent study [25], this suggests the importance of considering individuals' motivational and cognitive differences in the assessment of mixed communication surrounding e-cigarettes.

Supplementary Materials: The following are available online at https:/ /www.mdpi.com/article/10 .3390/ijerph18116094/s1, Figure S1: Message stimuli.

Author Contributions: Conceptualization, B.Y.; Analysis, B.Y.; Writing-Original Draft Preparation, B.Y., J.L.B., and Y.C.; Writing-Review and Editing, B.Y., J.L.B., and Y.C. All authors have read and agreed to the published version of the manuscript.

Funding: Data collection was supported by the National Institute on Drug Abuse of the National Institutes of Health and Food and Drug Administration Center for Tobacco Products under Grant P50DA036128. The content is solely the responsibility of the authors and does not necessarily represent the official views of the National Institutes of Health or the Food and Drug Administration.

Institutional Review Board Statement: The study was conducted according to the guidelines of the Declaration of Helsinki and approved by the Institutional Review Board of Georgia State University (IRB number: H18570; approval date: 06/05/2018).

Informed Consent Statement: Informed consent was obtained from all subjects involved in the study.

Data Availability Statement: The data are available upon reasonable request.

Conflicts of Interest: The authors declare no conflict of interest.

\section{References}

1. National Academies of Sciences, Engineering, and Medicine. Public Health Consequences of E-Cigarettes; The National Academies Press: Washington, DC, USA, 2018.

2. McNeill, A.; Brose, L.S.; Calder, R.; Bauld, L.; Robson, D. Evidence Review of e-Cigarettes and Heated Tobacco Products 2018. A Report Commissioned by Public Health England; Public Health England: London, UK, 2018.

3. Goniewicz, M.L.; Gawron, M.; Smith, D.M.; Peng, M.; Jacob, P.; Benowitz, N.L. Exposure to nicotine and selected toxicants in cigarette smokers who switched to electronic cigarettes: A longitudinal within-subjects observational study. Nicotine Tob. Res. 2017, 19, 160-167. [CrossRef]

4. Jay, J.; Pfaunmiller, E.L.; Huang, N.J.; Cohen, G.; Graff, D.W. Five-day changes in biomarkers of exposure among adult smokers after completely switching from combustible cigarettes to a nicotine-salt pod system. Nicotine Tob. Res. 2020, 22, 1285-1293. [CrossRef]

5. Pulvers, K.; Nollen, N.L.; Rice, M.; Schmid, C.H.; Qu, K.; Benowitz, N.L.; Ahluwalia, J.S. Effect of pod e-cigarettes vs cigarettes on carcinogen exposure among African American and latinx smokers: A randomized clinical trial. JAMA Netw. Open 2020, 3 , e2026324. [CrossRef]

6. Lindblom, E.N. Should FDA try to move smokers to e-cigarettes and other less-harmful tobacco products and, if so, how? Food Drug Law J. 2018, 73, 276-318. 
7. Abrams, D.B.; Glasser, A.M.; Pearson, J.L.; Villanti, A.C.; Collins, L.K.; Niaura, R.S. Harm minimization and tobacco control: Reframing societal views of nicotine use to rapidly save lives. Annu. Rev. Public Health 2018, 39, 193-213. [CrossRef] [PubMed]

8. Gottlieb, S.; Zeller, M. A nicotine-focused framework for public health. N. Engl. J. Med. 2017, 377, 1111-1114. [CrossRef] [PubMed]

9. Electronic Cigarettes: What's the Bottom Line? Available online: https://www.cdc.gov/tobacco/basic_information/e-cigarettes/ pdfs/Electronic-Cigarettes-Infographic-p.pdf (accessed on 3 June 2021).

10. Draft Guidance for Industry: Modified Risk Tobacco Product Applications; U.S. Food and Drug Administration: Washington, DC, USA, 2012.

11. Modified Risk Tobacco Products. Available online: https://www.fda.gov/tobacco-products/advertising-and-promotion/ modified-risk-tobacco-products (accessed on 3 June 2021).

12. Modified Risk Orders. Available online: https://www.fda.gov/tobacco-products/advertising-and-promotion/modified-riskorders (accessed on 3 June 2021).

13. "Covered" Tobacco Products and Roll-Your-Own/Cigarette Tobacco Labeling and Warning Statement Requirements. Available online: https: / /www.fda.gov/tobacco-products/labeling-and-warning-statements-tobacco-products/covered-tobaccoproducts-and-roll-your-own-cigarette-tobacco-labeling-and-warning-statement (accessed on 3 June 2021).

14. Carpenter, D.M.; Geryk, L.L.; Chen, A.T.; Nagler, R.H.; Dieckmann, N.F.; Han, P.K. Conflicting health information: A critical research need. Health Expect. 2016, 19, 1173-1182. [CrossRef] [PubMed]

15. Katz, S.J.; Lindgren, B.; Hatsukami, D. E-cigarettes warning labels and modified risk statements: Tests of messages to reduce recreational use. Tob. Regul. Sci. 2017, 3, 445-458. [CrossRef]

16. Owusu, D.; Lawley, R.; Yang, B.; Henderson, K.; Bethea, B.; LaRose, C.; Stallworth, S.; Popova, L. 'The lesser devil you don't know': A qualitative study of smokers' responses to messages communicating comparative risk of electronic and combusted cigarettes. Tob. Control 2020, 29, 217-223. [CrossRef]

17. Wackowski, O.A.; Rashid, M.; Greene, K.L.; Lewis, M.J.; O'Connor, R.J. Smokers' and young adult non-smokers' perceptions and perceived impact of snus and e-cigarette modified risk messages. Int. J. Environ. Res. Public Health 2020, 17, 6807. [CrossRef]

18. Katz, S.J.; Erkkinen, M.; Lindgren, B.; Hatsukami, D. Assessing the impact of conflicting health warning information on intentions to use e-cigarettes-An application of the heuristic-systematic model. J. Health Commun. 2018, 23, 874-885. [CrossRef] [PubMed]

19. Nagler, R.H.; LoRusso, S.M. Conflicting information and message competition in health and risk messaging. In The Oxford Encyclopedia of Health and Risk Message Design and Processing; Parrott, R.L., Ed.; Oxford University Press: New York, NY, USA, 2017.

20. Nagler, R.H.; Yzer, M.C.; Rothman, A.J. Effects of Media Exposure to Conflicting Information about Mammography: Results from a population-based survey experiment. Ann. Behav. Med. 2019, 53, 896-908. [CrossRef] [PubMed]

21. Lee, C.-j.; Nagler, R.H.; Wang, N. Source-specific exposure to contradictory nutrition information: Documenting prevalence and effects on adverse cognitive and behavioral outcomes. Health Commun. 2018, 33, 453-461. [CrossRef] [PubMed]

22. Chang, C. Motivated processing: How people perceive news covering novel or contradictory health research findings. Sci. Commun. 2015, 37, 602-634. [CrossRef]

23. Tan, A.S.; Lee, C.-J.; Bigman, C.A. Public support for selected e-cigarette regulations and associations with overall information exposure and contradictory information exposure about e-cigarettes: Findings from a national survey of US adults. Prev. Med. 2015, 81, 268-274. [CrossRef]

24. Tan, A.S.; Lee, C.-J.; Nagler, R.H.; Bigman, C.A. To vape or not to vape? Effects of exposure to conflicting news headlines on beliefs about harms and benefits of electronic cigarette use: Results from a randomized controlled experiment. Prev. Med. 2017, 105, 97-103. [CrossRef]

25. Yang, Q.; Herbert, N.; Yang, S.; Alber, J.; Ophir, Y.; Cappella, J.N. The role of information avoidance in managing uncertainty from conflicting recommendations about electronic cigarettes. Commun. Monogr. 2020, 1-23. [CrossRef]

26. Leeper, T.J.M.; Kevin, J. Motivated reasoning. In Oxford Biliographices, 22 February 2018 ed.; Oxford University Press: New York, NY, USA, 2018.

27. Lord, C.G.; Taylor, C.A. Biased assimilation: Effects of assumptions and expectations on the interpretation of new evidence. Soc. Personal. Psychol. Compass 2009, 3, 827-841. [CrossRef]

28. Kahan, D.M.; Braman, D.; Cohen, G.L.; Gastil, J.; Slovic, P. Who fears the hpv vaccine, who doesn't, and why? An experimental study of the mechanisms of cultural cognition. Law Hum. Behav. 2010, 34, 501-516. [CrossRef] [PubMed]

29. Nan, X.; Daily, K. Biased assimilation and need for closure: Examining the effects of mixed blogs on vaccine-related beliefs. $J$. Health Commun. 2015, 20, 462-471. [CrossRef] [PubMed]

30. Lord, C.G.; Ross, L.; Lepper, M.R. Biased assimilation and attitude polarization: The effects of prior theories on subsequently considered evidence. J. Personal. Soc. Psychol. 1979, 37, 2098-2109. [CrossRef]

31. Kahan, D.M.; Braman, D. Cultural cognition and public policy. Yale Law Policy Rev. 2006, 24, 149-172.

32. Greitemeyer, T.; Fischer, P.; Frey, D.; Schulz-Hardt, S. Biased assimilation: The role of source position. Eur. J. Soc. Psychol. 2009, 39, 22-39. [CrossRef]

33. Mafael, A.; Gottschalk, S.A.; Kreis, H. Examining biased assimilation of brand-related online reviews. J. Interact. Mark. 2016, 36, 91-106. [CrossRef]

34. Boysen, G.A.; Vogel, D.L. Biased assimilation and attitude polarization in response to learning about biological explanations of homosexuality. Sex Roles 2007, 57, 755-762. [CrossRef] 
35. Corner, A.; Whitmarsh, L.; Xenias, D. Uncertainty, scepticism and attitudes towards climate change: Biased assimilation and attitude polarisation. Clim. Chang. 2012, 114, 463-478. [CrossRef]

36. Ofori-Parku, S.S. Fifty years after surgeon general's report: Cultural cognition, biased assimilation, and cigarette smoking risk perceptions among college students. HealthRisk Soc. 2020, 22, 156-176. [CrossRef]

37. Boysen, G.A.; Vogel, D.L. Education and mental health stigma: The effects of attribution, biased assimilation, and attitude polarization. J. Soc. Clin. Psychol. 2008, 27, 447-470. [CrossRef]

38. Lopes, L.; Hamel, L.; Kearney, A.; Brodie, M. Data Note: Public Views on Vaping and e-Cigarettes; Henry Kaiser Family Foundation: San Franscisco, CA, USA, 2019.

39. Kahan, D.M.; Slovic, P.; Braman, D.; Gastil, J.; Cohen, G.L.; Kysar, D.A. Biased assimilation, polarization, and cultural credibility: An experimental study of nanotechnology risk perceptions. Harv. Law Sch. Program Risk Regul. Res. Pap. 2008. [CrossRef]

40. FDA Authorizes Marketing of iqos Tobacco Heating System with 'Reduced Exposure' Information. Available online: https: / / www.fda.gov / news-events / press-announcements/fda-authorizes-marketing-iqos-tobacco-heating-system-reducedexposure-information (accessed on 9 May 2021).

41. Kruglanski, A.W. Lay epistemic theory in social-cognitive psychology. Psychol. Inq. 1990, 1, 181-197. [CrossRef]

42. Briñol, P.; Petty, R.E. Individual differences in attitude change. In The Handbook of Attitudes; Albarracín, B.T.J., Zanna, M.P., Eds.; Psychology Press: New York, NY, USA, 2014; pp. 575-615.

43. Kruglanski, A.W.; Webster, D.M. Motivated closing of the mind: "Seizing" and "freezing". Psychol. Rev. 1996, 103, 263-283. [CrossRef] [PubMed]

44. O'Keefe, D.J. Persuasion: Theory and Research; Sage Publications: Thousand Oaks, CA, USA, 2016.

45. Webster, D.M.; Kruglanski, A.W. Individual differences in need for cognitive closure. J. Personal. Soc. Psychol. 1994, 67, 1049-1062. [CrossRef]

46. Webster, D.M.; Kruglanski, A.W. Cognitive and social consequences of the need for cognitive closure. Eur. Rev. Soc. Psychol. 1997, 8, 133-173. [CrossRef]

47. Sweeny, K.; Melnyk, D.; Miller, W.; Shepperd, J.A. Information avoidance: Who, what, when, and why. Rev. Gen. Psychol. 2010, 14, 340-353. [CrossRef]

48. Hart, W.; Adams, J.M.; Burton, K.A.; Shreves, W.; Hamilton, J.C. Shaping reality vs hiding from reality: Reconsidering the effects of trait need for closure on information search. J. Res. Personal. 2012, 46, 489-496. [CrossRef]

49. Hiel, A.V.; Mervielde, I. Effects of ambiguity and need for closure on the acquisition of information. Soc. Cogn. 2002, 20, 380-408. [CrossRef]

50. Yang, B.; Popova, L. Communicating risk differences between electronic and combusted cigarettes: The role of the FDA-mandated addiction warning and a nicotine fact sheet. Tob. Control 2020, 29, 663-671. [CrossRef]

51. Yang, B.; Owusu, D.; Popova, L. Effects of a nicotine fact sheet on perceived risk of nicotine and e-cigarettes and intentions to seek information about and use e-cigarettes. Int. J. Environ. Res. Public Health 2020, 17, 131. [CrossRef]

52. Popova, L.; Ling, P.M. Nonsmokers' responses to new warning labels on smokeless tobacco and electronic cigarettes: An experimental study. BMC Public Health 2014, 14, 1-10. [CrossRef]

53. Padon, A.A.; Lochbuehler, K.; Maloney, E.K.; Cappella, J.N. A randomized trial of the effect of youth appealing e-cigarette advertising on susceptibility to use e-cigarettes among youth. Nicotine Tob. Res. 2018, 20, 954-961. [CrossRef]

54. Sangalang, A.; Volinsky, A.C.; Liu, J.; Yang, Q.; Lee, S.J.; Gibson, L.A.; Hornik, R.C. Identifying potential campaign themes to prevent youth initiation of e-cigarettes. Am. J. Prev. Med. 2019, 56, S65-S75. [CrossRef]

55. Clawson, A.H.; McQuaid, E.L.; Dunsiger, S.; Borrelli, B. Smokers with children with asthma: Parental perceptions about prototype intervention messages focused on reducing child tobacco exposure and use. J. Child Health Care 2018, 24, 106-122. [CrossRef] [PubMed]

56. Global Community Panel Book. Available online: https://tolunacorporate.com/wp-content/uploads/2021/04/GlobalCommunity-Panel-Book.pdf (accessed on 3 June 2021).

57. Yang, B.; Owusu, D.; Popova, L. Testing messages about comparative risk of electronic cigarettes and combusted cigarettes. Tob. Control 2019, 28, 440-448. [CrossRef] [PubMed]

58. Witte, K. Predicting risk behaviors: Development and validation of a diagnostic scale. J. Health Commun. 1996, 1, 317-342. [CrossRef]

59. Roets, A.; Van Hiel, A. Item selection and validation of a brief, 15-item version of the need for closure scale. Personal. Individ. Differ. 2011, 50, 90-94. [CrossRef]

60. Carpenter, M.J.; Hughes, J.R.; Solomon, L.J.; Callas, P.W. Both smoking reduction with nicotine replacement therapy and motivational advice increase future cessation among smokers unmotivated to quit. J. Consult. Clin. Psychol. 2004, 72, 371-381. [CrossRef]

61. Heatherton, T.F.; Kozlowski, L.T.; Frecker, R.C.; Fagerstrom, K.O. The Fagerström test for nicotine dependence: A revision of the fagerstrom tolerance questionnaire. Br. J. Addict. 1991, 86, 1119-1127. [CrossRef] [PubMed]

62. Hayes, A.F. Introduction to Mediation, Moderation, and Conditional Process Analysis: A Regression-Based Approach, 2nd ed.; Guilford Press: New York, NY, USA, 2018.

63. Schumpe, B.M.; Brizi, A.; Giacomantonio, M.; Panno, A.; Kopetz, C.; Kosta, M.; Mannetti, L. Need for cognitive closure decreases risk taking and motivates discounting of delayed rewards. Personal. Individ. Differ. 2017, 107, 66-71. [CrossRef] 
64. Huang, J.; Feng, B.; Weaver, S.R.; Pechacek, T.F.; Slovic, P.; Eriksen, M.P. Changing perceptions of harm of e-cigarette vs cigarette use among adults in 2 US national surveys from 2012 to 2017. JAMA Netw. Open 2019, 2, e191047. [CrossRef]

65. Strickland, A.A.; Taber, C.S.; Lodge, M. Motivated reasoning and public opinion. J. Health Politics Policy Law 2011, 36, 935-944. [CrossRef]

66. Willson, V.L.; Kim, E.S. Pretest sensitization. In Encyclopedia of Research Design; Salkind, N.J., Ed.; Sage Publications: Thousand Oaks, CA, USA, 2012; pp. 1092-1094.

67. Jackson, S.; Jacobs, S. Generalizing about messages: Suggestions for design and analysis of experiments. Hum. Commun. Res. 1983, 9, 169-191. [CrossRef]

68. Rains, S.A.; Levine, T.R.; Weber, R. Sixty years of quantitative communication research summarized: Lessons from 149 metaanalyses. Ann. Int. Commun. Assoc. 2018, 42, 105-124. [CrossRef]

69. Snyder, L.B. How effective are mediated health campaigns. Public Commun. Campaign. 2001, 3, 181-190. [CrossRef]

70. Stiff, J.B.; Mongeau, P.A. Persuasive Communication, 3rd ed.; Guilford Press: New York, NY, USA, 2016.

71. Cole-Lewis, H.; Pugatch, J.; Sanders, A.; Varghese, A.; Posada, S.; Yun, C.; Schwarz, M.; Augustson, E. Social listening: A content analysis of e-cigarette discussions on twitter. J. Med. Internet Res. 2015, 17, e243. [CrossRef]

72. Kim, K.; Gibson, L.A.; Williams, S.; Kim, Y.; Binns, S.; Emery, S.L.; Hornik, R.C. Valence of media coverage about electronic cigarettes and other tobacco products from 2014 to 2017: Evidence from automated content analysis. Nicotine Tob. Res. 2020, 22, 1891-1900. [CrossRef] [PubMed] 